\title{
AGUA PASADA MUEVE MOLINO: LA (AUTO)REESCRITURA BIZANTINA, DE LOPE DE VEGA A CASTILLO SOLÓRZANO
}

\author{
Daniel Fernández Rodríguez \\ Universitat de València \\ Valencia, España \\ daniel.fernandez.tejerina@gmail.com
}

\begin{abstract}
RESUMEN / ABSTRACT
Este artículo obedece a un doble objetivo. Por un lado, pretende trazar la estela que la comedia bizantina de Lope La viuda, casada y doncella pudo dejar-sola o a través de la novela Guzmán el Bravo- en la narrativa de Alonso de Castillo Solórzano, fundamentalmente en dos de sus novelas: El bien hacer no se pierde (Noches de placer, 1631) y La ingratitud castigada (La quinta de Laura, 1649). Por otro, procura desgranar el profundo proceso de reescritura y autoreescritura que incumbe a esta última novela, en la que Castillo reelabora materiales tomados no solo de las obras citadas, sino también de otros dos relatos suyos, La libertad merecida (Jornadas alegres, 1626) y Amor con amor se paga (Los alivios de Casandra, 1640), hasta componer un rico mosaico intertextual con teselas de aquí y allá, propias y ajenas.
\end{abstract}

Palabras clave: La viuda, casada y doncella, Guzmán el Bravo, Castillo Solórzano, El bien hacer no se pierde, La ingratitud castigada.

\section{A MILL CAN GRIND WITH WATER THAT IS PAST: BYZANTINE (SELF)REWRITING, FROM LOPE DE VEGA TO CASTILLO SOLÓRZANO}

This article has two main goals. Firstly, it will examine the influence of the Byzantine plot of Lope de Vega's La viuda, casada y doncella and Guzmán el Bravo on two novellas by Castillo Solórzano: El bien hacer no se pierde (Noches de placer, 1631) and La ingratitud castigada (La quinta de Laura, 1649). Secondly, it will explore the (re)writing process of the latter novella, since Castillo Solórzano not only draws on the above-mentioned works, but also on two short stories of his own creation: La libertad merecida (Jornadas alegres, 1626) and Amor con amor se paga (Los alivios de Casandra, 1640). 
KEYWORDS: La viuda, casada y doncella, Guzmán el Bravo, Castillo Solórzano, El bien hacer no se pierde, La ingratitud castigada.

Recepción: 22/05/2020

Aprobación: 12/06/2020

“... El prodigioso ingenio, padre de las Musas, admiración de España y de las naciones extranjeras, Lope de Vega Carpio, de quien sabía los más de sus dulces versos de memoria...". La alabanza puede hoy parecernos desmedida, pero no debieron de sentirla así los lectores que en 1629 se hicieran con un ejemplar del Lisardo enamorado, novela en la que Alonso de Castillo Solórzano quiso rendir franco homenaje -y pagar con la misma moneda, dicho sea de paso- a uno de sus principales modelos y valedores, el Fénix de los Ingenios ${ }^{1}$. Tal confesión se explica no solo por un magisterio, el de Lope, que, viejos achaques y pájaros nuevos aparte, era a la sazón notorio y reconocido, sino porque entonces la memoria, lejos de ser como hoy un don envidiable o una destreza adquirida, era sencillamente la mejor manera de leer, pues ejercitaba al lector en la retención, asimilación y, a la postre, imitación, en un tiempo en que cualquier ingenio de buena fe asumía sin rasgarse las vestiduras que todo acto de escritura implicaba reescribir a clásicos y modernos, y, en el caso de autores tan prolíficos como Castillo Solórzano, sin duda también a sí mismos. Lo comprobaremos en estas páginas.

Los dulces versos de Lope que tanto pondera el de Tordesillas no discurrían solo por los cauces poéticos al uso, sino también por las concurridas veredas del teatro, que por aquel entonces atravesaban tanto los corrales de comedias como las imprentas y librerías. Ese es el caso de La viuda, casada $y$ doncella, pieza de Lope que pudo dejar honda huella en el andar literario del novelista. Pero la emulación, en literatura, ha consistido siempre no en la velada imitación de una sola fuente, sino en el hábil rastreo, ensamblaje y pulimento de materiales de distinta procedencia. Observaremos así cómo, en paralelo al de la Viuda, parece notable sobre Castillo el influjo de Guzmán el Bravo, una de las hoy conocidas como Novelas a Marcia Leonarda. Se examinarán también distintos procesos de auto-reescritura protagonizados por

\footnotetext{
El quinto de los ocho capítulos del Lisardo enamorado constituye una reescritura de la Arcadia, la entonces afamada novela pastoril de Lope, según explica al detalle Castillo Martínez (La Arcadia 100), que aduce además los encomios transcritos - procedentes del propio Lisardo enamorado (236) - y las generosas palabras que se dedicaron uno y otro escritor.
} 
el vallisoletano, que no solo acudía a obras ajenas en busca de las musas. Todo ello se percibirá en las dos novelitas bizantinas objeto de nuestro estudio: El bien hacer no se pierde (Noches de placer, 1631) y La ingratitud castigada (La quinta de Laura, 1649). En esta última, sorprenderemos a Castillo reelaborando materiales tomados no solo de las obras citadas, sino también de otras dos novelas suyas: La libertad merecida (Jornadas alegres, 1626) y Amor con amor se paga (Los alivios de Casandra, 1640). Secundariamente, trazaremos unas pinceladas sobre Lisardo enamorado (1629).

\section{DE LA VIUDA, CASADA Y DONCELLA Y GUZMÁN EL BRAVO AL LISARDO ENAMORADO}

Las correrías del Guzmán lopesco, impresas en La Circe (1624), son bien conocidas y no precisan por ahora de más presentaciones. No tan recordada en cambio es La viuda, casada y doncella. Desde que Lope rematara su escritura el 22 de octubre de 1597 (Iriso Ariz 107), todo apunta a que se mantuvo en el repertorio de Luis de Vergara durante cerca de veinte años ${ }^{2}$, indicio tal vez de una acogida favorable entre los asistentes a los corrales. Tan calurosa acaso como la que debió de recibir tras su inclusión en la Parte VII(1617) de comedias $^{3}$, a juzgar por las distintas reescrituras a las que de manera más o menos directa dio origen: un fragmento de La vida del escudero Marcos de Obregón (1618), de Vicente Espinel; La desdicha en la constancia, novela de Miguel Moreno publicada en 1624; e, incluso, dos novelas del propio Lope incluidas en el seno de La Circe ese mismo año, La prudente venganza y Guzmán el Bravo, deudoras asimismo de la comedia ${ }^{4}$. Tan granada cosecha de (auto)reescrituras se explica mejor a la luz del conspicuo desembarco del género bizantino en las letras españolas a partir justamente de 1617, tanto en

\footnotetext{
Para reconstruir la trayectoria escénica de la pieza, es necesario acudir a Feit y McGrady (144 y 191) y al DICAT, dirigido por Teresa Ferrer.

La Parte hubo de imprimirse los últimos días de 1616: aunque casi todos los ejemplares lucen la fecha de 1617 en su portada, al menos uno lleva la de aquel año (Di Pastena 20-21).

Para más detalles acerca de los pasajes concretos de estas novelas que delatan dicho influjo, remito a Fernández Rodríguez (Lope de Vega y La viuda), donde se completan las valiosas inquisiciones de Feit y McGrady (23) a propósito de La prudente venganza. Para el Marcos de Obregón, acúdase a Feit.
} 
la novela -larga y corta- como en el teatro impreso; un género, el bizantino, que en los años veinte y treinta del siglo XVII sería una de las modas literarias de más filón para los libreros y mayor regocijo para los lectores 5 .

En 1629, el taller valenciano de Juan Crisóstomo Garriz alumbró el Lisardo enamorado. Como advierte temeroso el propio Castillo (57), se trata de "una novela [...] preñada de muchas", lo que le permite salpimentarla con "múltiples géneros" (Giorgi, El Lisardo) ${ }^{6}$. Así, el libro sexto engarza varios motivos bizantinos (González Rovira, La novela 251) y de la literatura de cautiverio $^{7}$, algunos de los cuales remiten a la historia del capitán cautivo inserta en el Quijote (Camamis 198 y Teijeiro 46).

Con todo, en la segunda parte de este capítulo podrían resonar también ecos de La viuda, casada y doncella. En él, la cautiva Gerarda narra cómo su enamorado Lisardo, ciego por celos infundados, apuñaló a Rodrigo, hermano de la dama, por lo que, según le han contado a ella, tuvo que partir hacia Barcelona y embarcarse rumbo a Italia (en la comedia de Lope, Feliciano se ve obligado a huir hacia tierras transalpinas después de haber acuchillado, en defensa propia, al hermano de su rival amoroso). Una vez recuperado, Rodrigo navega junto a Gerarda en dirección a Nápoles, pero unos corsarios los capturan y los llevan a Argel, donde los retienen como cautivos (una suerte pareja corre Feliciano, no su dama, que se queda en tierra). La historia discurre luego por otros derroteros ${ }^{8}$. Tales similitudes responden en buena

5 Acerca de los avatares de la novela bizantina, véanse la tesis y el libro de González Rovira, referencia inexcusable; para el desarrollo del género en la novela corta y el teatro, así como sobre el papel desempeñado por Lope en tal proceso, puede verse Fernández Rodríguez (Entre corsarios).

6 Agradezco a Giulia Giorgi que me haya facilitado amablemente la consulta de su trabajo.

Me centro aquí en el Lisardo, y no en la que podría considerarse su primera versión o redacción, los Escarmientos de amor moralizados (Sevilla, 1628), libro organizado en siete capítulos (uno menos que el Lisardo, si bien la materia argumental no es menor), al término de cada cual se incluyen unos aprovechamientos morales desaparecidos en la refundición de 1629. El capítulo sexto del Lisardo se corresponde con la primera parte de este mismo capítulo en los Escarmientos (ff. 121v-132r), que, más allá de cambios lingüísticos y estilísticos y alguna que otra añadidura u omisión de poco relieve, no entraña diferencias notorias en la trama (LaGrone; Giorgi, Alonso y El Lisardo; Castillo Martínez, La Arcadia).

Tras un intento fallido de fuga, a Rodrigo lo mandan como forzado a una galera, mientras que a Gerarda la rescata un padre redentor; ambos, sin embargo, logran reunirse en el puerto de Barcelona tras una contienda naval que enfrenta a sus respectivas embarcaciones. En la Viuda, en cambio, Feliciano logra escapar y regresa a Valencia. 
medida a tópicos literarios de la época, conque no pueden esgrimirse como pruebas para sustentar una filiación. No obstante, a juzgar por paralelismos más acusados en textos posteriores de Castillo, acaso podríamos hallarnos frente a un primer recuerdo -lejano, eso sí- de la Viuda.

Otro tanto vale decir respecto a uno de los herederos de esta comedia, Guzmán el Bravo, que recrea asimismo el encadenamiento de lances aducido ${ }^{9}$ y presenta además una escena en la que don Felis, como respuesta a unos palos recibidos por su buen amo de parte de un moro, "le dio una puñada en los pechos de las que él solía, con que le dejó por dos horas sin habla" (22526), reacción muy similar a la de Rodrigo (nombre por cierto que adopta don Felis durante su cautiverio):

[...] como los bríos de soldado no los perdiese en medio de sus trabajos, un día se descompuso con el moro sobrestante de la fábrica en que asistía, y diole con una caña no sé cuántos palos; mas mi hermano, ofendido de aquel oprobio, tomando una pesada piedra, le dio con ella de modo que le dejó sin sentido alguno (Lisardo enamorado 253) ${ }^{10}$.

Más adelante hablaremos de las razones que justificarían con creces el interés de Castillo por la Viuda y Guzmán el Bravo. Ocupémonos ahora de la siguiente novela.

\section{CAMINOS QUE CONVERGEN: EL BIEN HACER NO SE PIERDE (1631)}

En 1631 vio la luz Noches de placer, conjunto de novelas entre las que se cuenta El bien hacer no se pierde, de inequívoco sabor bizantino (González

9 Don Felis se defiende de Leonelo, al que hiere de muerte, por lo que inicia una vida de soldado y, tras varias peripecias, sufre una tormenta que se salda con su captura y cautiverio en tierras musulmanas.

10 La primera versión de este pasaje, correspondiente a los Escarmientos de amor moralizados (1628), presenta variantes de cierto interés: "Sucedió pues que, como los bríos de soldado no los perdiese aun en medio de sus trabajos, descomponiéndose él con un moro sobrestante de aquella fábrica en que asistía, diole con una caña dos o tres palos; mas mi hermano, en venganza de este agravio, le dio con un azadón en la cabeza, dejándole tendido a sus pies, sin sentido alguno". Cito por la prínceps (f. 129r), pero modernizo la ortografía y la puntuación. 
Rovira, "La novela" 951). En ella, las posibles reminiscencias de La viuda son ya más acusadas. Al margen de las obvias diferencias en su desarrollo, ambos textos comparten un mismo armazón argumental, que podría resumirse del siguiente modo: un galán, correspondido por su dama pese a la pobreza en la que está sumido, se ve obligado a marcharse de Valencia, lo que apena profundamente a su amada. En el transcurso del viaje, una violenta tempestad provoca el naufragio de la nave, episodio que se salda con la captura del joven a manos de un corsario. Durante su cautiverio, desdeña el amor de una mora que bebe los vientos por él. Por su parte, la dama trata de postergar el casamiento que su padre y el rival de su amado ansían llevar a cabo. Pasado un tiempo, el protagonista logra regresar a Valencia y, tras vencer una serie de obstáculos, ambos pueden al fin casarse.

La presencia y concatenación de tantos episodios comunes exigen no pasarlos por encima sin más y obligan a considerar la hipótesis de una reescritura, incluso concediendo que muchos reflejen tópicos de regusto bizantino, tan encumbrados por aquel entonces. No hace al caso detallar ahora una por una las notables divergencias argumentales entre ambas obras; baste advertir el papel antagónico en el Bien hacer de don Cotaldo, hermano y rival amoroso del protagonista, y causante de que este deba embarcarse como capitán hacia Mallorca, viaje naval que en la Viuda se produce, ya lo sabemos, como consecuencia de un altercado mortal ${ }^{11}$. Este lance de la comedia formaba parte ya del abecé narrativo del tordesillano, pues en el Lisardo echó mano de una situación muy similar para forzar el viaje del galán. Sin embargo, en el Bien hacer decidió tomar otros vericuetos narrativos: no querría seguir fielmente un único modelo, sino más bien engastar ideas de aquí y allá.

Justamente, otra posible fuente de esta novela es Guzmán el Bravo. De nuevo, las diferencias argumentales son considerables. Sobre todo respecto a la segunda parte del relato de Lope, que toma un sesgo más afín a la literatura caballeresca, y también en lo que atañe al papel de la protagonista: Felicia, que no conquista el corazón de don Felis, se disfraza de paje para acompañarlo en sus peripecias, decisión que contrasta con la actuación de Clavela en la Viuda y doña Laura en el Bien hacer, caracterizada por su fiel

11 Muy diferente asimismo es el regreso a Valencia del protagonista: mientras que en la Viuda llega justo a tiempo de interrumpir el casamiento, en el Bien hacer se presenta con unos días de antelación, por lo que en primer lugar desentierra el tesoro que le había prometido el moro que lo liberó del cautiverio, concierta entonces con su dama que esta finja un achaque el día de su boda y, por fin, ambos se reúnen en secreto. 
espera en Valencia y por desdeñar al esposo propuesto por su familia. Y, con todo, cómo no reconocer en el Bien hacer una serie de episodios que, unidos a varios motivos de raigambre bizantina ya aludidos a propósito de la Viuda (el naufragio, la captura a manos de los corsarios, el cautiverio en tierras musulmanas o el vano amartelamiento de una mora, a los que cabría añadir la magnanimidad de un gran señor que libera a los cautivos y los colma de riquezas), podrían apuntalar la posibilidad de que Castillo se inspirara en la novela de Lope a la hora de componer la suya. Por supuesto, tales incidentes pertenecen al acervo bizantino, por lo que no permiten demostrar a ciencia cierta la relación directa entre uno y otro texto; como sea, además del rastro de Guzmán el Bravo en otros relatos de Castillo (Lepe García, El hibridismo 46), cuestión que habremos de retomar, cabría aducir otras correspondencias que se suman a la concatenación de los motivos descritos.

Para empezar, el suceso que en el Bien hacer prende el amor de la pareja protagonista (un incendio en una alquería del que don Jerónimo rescata a doña Laura y al moro que más tarde le concederá la libertad) podría ser un recuerdo de la triquiñuela urdida por don Felis y Felicia para ganar tiempo durante su cautiverio y esquivar así las pretensiones amorosas de la judía Susana. De hecho, en la escena ideada por Castillo es posible incluso rastrear ciertas reminiscencias verbales de Guzmán el Bravo, por más que respondan a situaciones previsibles durante un incendio ${ }^{12}$. Claro está que una pluma tan ducha en la reescritura como la del tordesillano orilló la mera imitación y-de ser cierta nuestra conjetura- convirtió una treta urgida por las acechanzas sentimentales de una judía en un lastimoso incidente para inflamar el pecho de doña Laura y justificar la ulterior liberalidad del moro. Por cierto que unas palabras del rey de Túnez, dirigidas a don Felis en Guzmán el Bravo (228), acaso resuenen en un pasaje del Bien hacer (214): "no he de consentir que te hagan estos moros agravio, ni que pierdas la libertad que tan bien mereces"; "quiero usar del segundo [fin], que es daros libertad y aun hacienda con que viváis, porque sé que no tenéis lo que merecéis". El remanso tras la tormenta se narra también en términos similares: si don Felis y su paje

12 Así, si los cautivos fingieron que el fuego se originó "por algún descuido", el incendio en la alquería se produjo "por descuido de una criada"; para alertar a los demás, "dio voces don Felis", lo mismo que doña Laura y su madre, que "dieron voces a sus criados"; finalmente, "acudiendo con cuidado, aunque fue más de lo que pensaron, remediaron el fuego", mientras que "acudió luego la gente, y con agua pudieron aplacar algo del fuego del aposento" (Lope, Guzmán 224 y Castillo, El bien hacer 204-05). 
"al alba reconocieron a un tiempo el cielo y la tierra, dando en la costa de Berbería", el bajel de don Jerónimo "al amanecer se halló muy cerca de la playa de Argel" (El bien hacer 208) ${ }^{13}$.

Me parece probable por tanto que Castillo se inspirara en La viuda, casada y doncella y Guzmán el Bravo para tejer su relato, aunque en ningún caso siguiera de un modo servil sus tramas. El armazón narrativo se asemeja más al de la comedia, pero la novela podría haber influido en ciertos detalles y resonancias verbales. Exploremos entonces las circunstancias que pudieron empujar a Castillo a tomar la senda de la reescritura.

\section{LAS RAZONES DE DON ALONSO: DE LOPE AL TURIA, DEL MAESTRO AL PÚBLICO}

Más allá del obvio interés que la pluma de Lope despertaba en cualquier letraherido de la época, a la hora de examinar las razones por las que Castillo pudo elegir obras del Fénix como modelo es preciso considerar su íntima relación, tanto personal como literaria. Si es que una y otra pueden deslindarse.

Castillo Solórzano formaba parte desde hacía años del círculo de intelectuales que orbitaba en torno a Lope, con quien había coincidido en Madrid -antes de partir hacia Valencia en 1628- a lo largo de los años veinte en las academias de Sebastián Francisco de Medrano y, más tarde, de Francisco Mendoza (López Gutiérrez 21-30). Enseguida hicieron buenas migas. No es de extrañar entonces que Lope diera la cara por él en más de una ocasión: en la relación de las fiestas celebradas por la canonización de San Isidro en $1622^{14}$, en sus elogiosas aprobaciones de los Donaires del

13 En el curso de la novela topamos con otras coincidencias, más allá de que respondan a circunstancias habituales durante el cautiverio, como el miedo que sienten los galanes ante la posibilidad de que pretendan cobrar un alto rescate por ellos. En fin, la condición del protagonista, nombrado capitán por el virrey, y la de su padre, caballero y antiguo combatiente en Flandes, podrían ser un recuerdo asimismo de Guzmán el Bravo, que hace honor a su apodo en esa y otras muchas regiones y contiendas.

14 En ella, Lope pondera los versos con los que participó nuestro autor: "Don Alonso del Castillo / fue de aquellos versos dueño, / en cuyo ingenio sabroso / vive un panal de los cielos" (Relación 152v). 
Parnaso de Castillo (1624 y 1625 $)^{15}$, o en las alabanzas que le dedica en el Laurel de Apolo $(1630)^{16}$. Don Alonso, uno de sus más fieles seguidores en la disputa contra los culteranos, no le iba a la zaga a Lope en lo que a elogios se refiere ${ }^{17}$; baste recordar las encendidas palabras del Lisardo (1629) o las apologías de Las harpías en Madrid $(1631)^{18}$.

Pero más aún que los generosos recuerdos mutuos nos interesan las también mutuas operaciones de reescritura, que refuerzan las hipótesis defendidas en estas páginas. Mencionemos en primer lugar la comedia lopesca Amar, servir y esperar, posiblemente escrita entre 1624 y 1635 (Morley y Bruerton 27778), cuya fuente es El socorro en el peligro, novela de Castillo impresa en 1625 en sus Tardes entretenidas (Campana xxxiv). Más interesante todavía es la profunda relación intertextual entre la también lopesca Amar sin saber a quién (1620-1622) ${ }^{19}$ y la novela titulada El amor por la piedad, que se imprimió en Huerta de Valencia en 1629; aunque las fechas parecerían indicar que Castillo se inspiró en Lope, se ha sugerido que el Fénix pudo tener acceso privilegiado a textos aún inéditos de su compañero de fatigas, por lo que tal filiación queda abierta a futuras indagaciones (Vaccari ${ }^{20}$. Del

15 Estos encomios "parecen ir mucho más allá de las habituales e hipócritas aclamaciones entre poetas y, por el contrario, parecen más bien fruto de verdadera admiración y amistad" (Rubio Árquez 47).

16 "Las Gracias en la cuna / de su dichosa infancia / tan risueñas vinieron / que a don Alonso del Castillo dieron / más gracia que fortuna, / y que premio, elegancia; / que tiene repugnancia / tal vez con la virtud; pero si miras / sus libros, sus papeles, superiores / a cuantos hoy de aquel estilo admiras, / llenos de tantas elegantes flores / como la copia de su fértil genio / con prodigioso ingenio / por el mundo derrama, / no le quieras más premio que su fama, / ni laureles mayores, / ni más ricos favores / que de su pluma la dorada copia, / que la virtud es premio de sí propia" (Laurel de Apolo, silva VIII, vv. 314-32).

17 Esta estrategia editorial, a caballo entre el gesto amistoso y la autopromoción personal (Monzó, Un dramaturgo 61), la describen muy bien Collantes, Özmen y Ruiz Pérez (16): "Castillo Solórzano y María de Zayas, además de este círculo, compartieron su adoración hacia Lope de Vega. Este, plenamente consciente de cómo el mecanismo revertía en el incremento de su importancia, escribió poemas laudatorios a algunos nuevos escritores como carta de presentación a la hora de entrar en el mercado; en el caso de nuestro autor, firmó la aprobación a su primera obra impresa".

18 Para las relaciones entre Lope y Castillo Solórzano, me baso fundamentalmente en Castillo Martínez (La Arcadia), Monzó (Un dramaturgo) y Vaccari.

19 Morley y Bruerton (270-71) comentan los problemas que entraña la hipotética fecha de escritura.

20 En cambio, la fecha de publicación más tardía del Bien hacer no invita a considerar tal posibilidad. 
mismo año, en fin, data el Lisardo, cuyo capítulo quinto, se ha dicho ya, reescribe la Arcadia de Lope. En definitiva, para cuando Castillo compuso el Bien hacer (y, desde luego, el Lisardo), la reescritura era un fenómeno que lo ligaba estrechamente a su maestro.

Resulta de todo punto natural que Castillo Solórzano recorriera con ardor las páginas de Guzmán el Bravo. Cuando, a mediados de los años veinte, Castillo se propuso asaltar los cielos novelísticos, por fuerza debía de conocer a los autores que habían forjado la tradición. La irrupción de las novelas cortas de Lope, que tanta cátedra había sentado ya en varios géneros, no pudo dejar indiferente a nadie. Menos aún a don Alonso. No en vano, se ha sugerido que la publicación de La Filomena (1621) y La Circe (1624), libros en los que Lope "lograba conciliar altura estilística y exigencias de la imprenta, pretensiones de mecenazgo y mercado", "pudieron servir de acicate para la salida de sus obras [las de Castillo] a la plaza pública" (Collantes, Özmen y Ruiz Pérez 6). En su afán por labrarse el favor de la alta nobleza, Lope incluyó sus novelas en "dos libros misceláneos destinados a un público culto, proponiéndolas casi como experimentos a un lector bien dispuesto a la reflexión" (Presotto 11), lo que acaso explique su parca tirada impresa ${ }^{21}$. Con todo, que tal vez no se ganaran a los sectores menos instruidos no menoscabó su alta estima literaria y su aprecio editorial, como lo prueba que las cuatro se incluyeran entre las ocho Novelas amorosas de los mejores ingenios de España (1648), nada menos que la primera antología de novelas cortas de varios autores publicada en España (González Ramírez, Lope de Vega) ${ }^{22}$. Guzmán el Bravo, como también Las fortunas de Diana y La desdicha por la honra, respondía además en no poca medida al patrón bizantino de viajes y cautivos, tan en boga en los años veinte y treinta. De hecho, en La libertad merecida, novela de Jornadas alegres (1626) con un episodio de cautiverio similar al del Bien hacer, Castillo toma el bosquejo de Guzmán el Bravo,

21 "El complejo ideario estético que planteó Lope tanto en La Filomena como en $\mathrm{La}$ Circe supuso una insoslayable tara editorial. La dificultad para aprehender el mensaje estéticoliterario que Lope quiso transmitir en estas obras [...] irremisiblemente lastró su circulación impresa, que quedó severamente limitada a solo dos ediciones de La Filomena y a una de La Circe" (González Ramírez, Lope de Vega 42).

22 Una de ellas, La desdicha por la honra, formó parte asimismo -con el título Los amantes sin fortuna - de la exitosa compilación Varios efectos de amor en once novelas ejemplares (Madrid, 1666). Para más detalles, véanse Copello, Presotto (29-31), González Ramírez (Una novela 33 y Lope de Vega 47-48) y Castillo Martínez (Falsificaciones). 
"que sin duda conocía y había leído" (Lepe García, El hibridismo 46) ${ }^{23}$. Así las cosas, no debe extrañarnos que, al ponerse manos a la obra con el Bien hacer, tuviera las hazañas de Guzmán poco menos que en la uña, como acaso reflejen los ecos verbales alegados.

Despidámonos del bravo y atendamos a la viuda. Para cuando Castillo dio a las prensas el Bien hacer, contaba ya la Viuda con un vasto bagaje, teatral y literario, por corrales y librerías, amén de gozar de un envidiable legado, cifrado en varios casos de reescritura (o, cuando menos, de estrecha intertextualidad), tanto propios (ahí está precisamente Guzmán el Bravo) como ajenos. Su fecunda trayectoria, prosapia lopesca y argumento bizantino la convertían en un partido irresistible. Pero hay algo más. ¿Por qué la Viuda pudo interesar a don Alonso precisamente hacia 1630, cuando hubo de pergeñar o rematar El bien hacer? Soplaba un viento nuevo en el levante.

En 1628, Castillo Solórzano se trasladó a la ciudad del Turia para acompañar, en calidad de maestresala, a Luis Fajardo de Requesens y Zúñiga, marqués de los Vélez, nombrado virrey de Valencia ese mismo año ${ }^{24}$. En cuanto Castillo pisó tierras valencianas (las de sus padres, por cierto), procuró ganarse el favor del público, recabar apoyos entre los hombres de letras y, en fin, afianzarse un mecenazgo individual y colectivo. Así se explican el ambiente local y el marco académico presentes ya en sus dos primeras obras publicadas en la capital del virreinato en la temprana fecha de 1629 (Lisardo enamorado y Huerta de Valencia), las numerosas poesías laudatorias firmadas por ingenios levantinos que encabezaban este último libro (Rubio Árquez), las múltiples y generosas alabanzas que Castillo dedicó a la ciudad de Valencia o el uso de apellidos de renombre local en sus ficciones (sin ir más lejos, los Centellas del Bien hacer $)^{25}$. Las Noches de placer (1631), si bien ya publicadas en Barcelona (donde pudo residir su autor entre ese año y 1633) ${ }^{26}$, responden también a esta misma maniobra; no en vano, todas y cada una de ellas están

23 Las semejanzas entre La libertad merecida y el Bien hacer se circunscriben al ámbito del cautiverio, y se cifran en ciertos motivos, recurrentes en este tipo de lances, en los que no procede insistir por ahora.

24 La información aducida en este párrafo procede fundamentalmente de Collantes, Özmen y Ruiz Pérez (17-18) y, sobre todo, de Monzó (Un dramaturgo y Un mapa).

25 Sobre la presencia de este apellido y el de otras familias valencianas, remito a Giorgi (Noches 73) y a Monzó (Un dramaturgo 64-66).

26 Giorgi (Noches 9) y Monzó (Un dramaturgo) aportan la bibliografía oportuna. 
"dirigidas a diversos títulos y caballeros de Valencia", según reza la portada ${ }^{27}$. Los títulos de algunas obras posteriores -Sagrario de Valencia, publicada en 1635, y Patrón de Alcira, de 1636- son muy elocuentes al respecto (Castillo Martínez, La escritura), y en esta misma operación se inscribe el volumen misceláneo titulado Fiestas del jardín, de 1634 (Festini y Monzó). Todo lo cual demuestra que "las coordenadas de la ciudad misma constituyen el fundamento referencial que hará germinar la simiente" de las obras compuestas durante su estancia en Valencia, que aportó a Castillo un "conocimiento literario y una experiencia que ejercerá influencia notable sobre la materia de sus escritos" (Monzó, Un dramaturgo 56).

En el contexto de tan ansiada difusión y promoción local en busca de público, mecenazgo y consolidación artística y personal, por fuerza el de Tordesillas hubo de imbuirse del ambiente libresco, teatral y literario de su nueva residencia ${ }^{28}$. Tal empeño podría muy bien pasar por leer cuantas novelas y comedias llevaran los escenarios valencianos al ámbito de la ficción, o cuando menos las de sus autores más queridos. No en vano, el período valenciano supuso para Castillo el aprendizaje del arte de escribir comedias -como demuestran El agravio satisfecho (impresa en 1629 en el seno de Huerta de Valencia) y las tres piezas incluidas en Fiestas del jardín

27 Este proceder contaba con algunos precedentes, como las novelle de Bandello o, en el caso de la inmediata tradición española, los Sucesos y prodigios de amor (1624) de Pérez de Montalbán, atinadamente aducidos como probable modelo de Castillo por Giorgi (Noches 19) y González Ramírez (Madrid 42). No me parece descabellado suponer que las Partes de Lope, cuyas comedias (doce justamente, como es bien sabido) se venían publicando con dedicatorias individuales desde la Trecena (1620), alentaran asimismo la estrategia seguida por Castillo en Noches de placer. El sentido político de las dedicatorias de esta colección ha sido iluminado por Cayuela y Gandoulphe.

28 Tengo muy presentes en todo momento las conclusiones de Collantes, Özmen y Ruiz Pérez (24) acerca de la carrera literaria de Castillo y de la "conciencia y premeditación con que da origen a su obra publicada, tardía en su aparición pero a todas luces bastante madurada en su gestación previa, lo que le permite a Castillo salir a la luz pública armado con casi todas las armas del autor”, así como el juicio y síntesis de González Ramírez (Madrid 43-44): “Que fuese capaz de controlar su producción, de prometer y cumplir, de elaborar proyectos en dos partes y de tener conciencia de grupo, es indicativo de que Castillo Solórzano [...] concibió su contribución a la narrativa como un programa literario que fue depurando obra tras obra; pero también revela que actuó como un escritor profesional (en tanto en cuanto fue capaz de poner su capacidad narrativa al servicio de estrategias socioliterarias), percibiéndose a sí mismo como parte de un sistema - de espacio literario, de poder y de mercado-al que le podía sacar rendimiento". 
(1634)-, así como una apuesta por el teatro impreso, en la estela de Lope ${ }^{29}$. El caso de El agravio satisfecho resulta particularmente ilustrativo, pues se trata de una reescritura de La fuerza de la sangre cervantina a partir, sobre todo, de la pieza homónima firmada por el valenciano Guillén de Castro (Escudero Baztán). Por lo demás, el influjo del teatro en sus novelas es notorio, particularmente en Noches de placer (Sileri y Giorgi, Noches 32-42). No es de extrañar entonces que, entre las lecturas (o, quién sabe, funciones teatrales) a las que se entregara, por ocio o por negocio, se contase también La viuda, casada y doncella, con cuyas aventuras ya debía de estar en cualquier caso familiarizado, pues campaban inmortalizadas desde hacía quince años en la Parte VII de comedias del Fénix. Tan "devoto seguidor de Lope" (Bonilla Cerezo 244) difícilmente pudo pasar por alto una obra de su maestro que, además de haber resultado más o menos exitosa, mezclaba entre sus versos el ambiente valenciano, los lances del cautiverio y las tan socorridas entonces peripecias bizantinas, lo mismo que las historias suyas que nos traemos entre manos. El subtítulo de la pieza constituía por sí mismo un reclamo para un autor interesado en tales ingredientes: "Pasa en Valencia y Berbería" (43). Admitámoslo: la evidencia textual no permite descartar que el recuerdo de la Viuda fuera más bien lejano o inconsciente. Pero, a decir verdad, al plan urdido por don Alonso a su llegada a Valencia, y sobre todo a una novela como el Bien hacer, una obra así le venía que ni pintada.

¿Implica todo ello que en la génesis del Bien hacer no pudieran intervenir otros modelos? Por supuesto que no. La conjunción de diversos materiales en un solo texto era procedimiento habitual en don Alonso, y ni qué decir tiene que tras el Bien hacer podrían latir más lecturas, asumidas siquiera de manera tácita en su bagaje como literato ${ }^{30}$. Entre las muchas obras de temática similar descuella La desdicha en la constancia ${ }^{31}$, novelita de sesgo bizantino publicada por Miguel Moreno en 1624 (lo mismo que Guzmán el Bravo y otras

29 "Él, el escritor de novelas más prolífico del siglo XVII, le otorga a la comedia, y al espacio del teatro, un papel fundamental en la literatura de entretenimiento con la incorporación de comedias para ser leídas" (Festini 223). Remito asimismo a las consideraciones de Fuentes Nieto (Alonso y Fiestas 15-18), editor de Fiestas del jardín.

30 Por ciertos episodios compartidos y su anclaje en Valencia, no me resisto a recordar la historia de Marcelio y Alcida, inserta en la Diana enamorada de Gil Polo, y la patraña IX de Timoneda. Para estas y otras posibles fuentes (novelle, etc.), remito a Fernández Rodríguez (Entre corsarios).

31 Para cuanto tenga que ver con este relato de Moreno, acúdase a González Ramírez (Una novela corta). 
de índole similar), verdadero annus mirabilis de la novela corta bizantina. Sus concomitancias con el Bien hacer son evidentes, por estar asimismo trazada sobre la falsilla de la Viuda (Fernández Rodríguez, La viuda). Desde luego, resulta difícil suponer que Castillo, conspicuo escritor de novelas, no diese buena cuenta de esta de Moreno, quien también revoloteaba alrededor del Fénix de los Ingenios. Volveremos a hablar de La desdicha.

DE EL BIEN HACER NO SE PIERDE A LA INGRATITUD CASTIGADA

En 1649 vieron la luz en Zaragoza dos libros póstumos de Castillo Solórzano: Sala de recreación (con aprobación fechada en 1639) y La quinta de Laura. Este último, que incluye La ingratitud castigada, se publicó "a costa de Matías de Lizau", nieto de una laboriosa estirpe de libreros (González Ramírez, Sobre la princeps 57-61). Son varios los problemas editoriales que aquejan a La quinta de Laura, muchos debidos al fallecimiento prematuro de su autor, ocurrido un año antes, en 1648, según el consenso crítico. Con su pericia acostumbrada, González Ramírez (Sobre la prínceps) ha disipado las sombras conjuradas por Emilio Cotarelo en torno a ciertas novelas, que en algún caso llegaban incluso a poner en duda la autoría de Castillo o a aseverar que se tratase de autoplagios descarados. Nada de eso.

Sí es cierto en cambio que algunos detalles plantean incógnitas de no poca enjundia y apuntalan la intervención de terceros en la confección final del libro, probablemente porque no llegó a superar "la última revisión del autor", por lo que su albacea debió de hacerse cargo "de colocar en el mercado aquellos libros que no habría podido ver publicados en vida" (González Ramírez, Sobre la prínceps 63 y 71). Así lo sugiere en primera instancia que la dedicatoria del volumen no la firmase Castillo, sino su editor-circunstancia de todo punto insólita en su carrera-, y otro tanto vale decir respecto al breve prólogo del volumen, que no constituye más que una versión algo reducida del que encabezaba Sala de recreación, cuya dedicatoria corrió a cargo también de su editor (González Ramírez, Sobre la prínceps 65). No menos sospechoso, en fin, es el título de la propia colección, que repite el de una novela de Castillo, originalmente publicada en 1627 con el nombre de La quinta de Diana, pero compilada justamente un año antes en Zaragoza -ya como La quinta de Laura- entre las Novelas amorosas de los mejores ingenios de España (1648), antología costeada por José Alfay y Martín Navarro, el primero de los cuales se encargó asimismo de editar 
Sala de recreación en $1649^{32}$. Tiempo habrá de volver sobre otros problemas de la colección: hora es ya de adentrarnos en el meollo argumental de La ingratitud castigada.

Más desde luego que por sus méritos literarios -algo menguados, como a menudo en don Alonso-, esta novelita es una delicia por su tejido intertextual. Para empezar, si por un lado deja sentir los ecos de la tradición instaurada por La viuda, casada y doncella y seguida por Guzmán el Bravo y La desdicha en la constancia, por otro se antoja fruto de un proceso de auto-reescritura respecto a El bien hacer no se pierde. En efecto, el esquema argumental que subyace a La ingratitud castigada es muy similar al que venimos analizando. Dos galanes se enzarzan en una contienda a cuenta de los amores de una dama, pendencia que se salda con la muerte de uno de ellos, por lo que el otro debe embarcarse y huir así de la justicia. Durante su viaje, unos corsarios le capturan y le llevan a Argel, donde se hace con sus servicios un señor moro, cuya hija se enamora perdidamente del cautivo. Don Garcerán resiste los embates amorosos y ofertas de apostasía y al fin logra escapar. Ya en Valencia, decide venderse como esclavo fingido y, de esa guisa, entra al servicio de su amada, a la que una y otra vez salva la vida. Gerarda, sin embargo, no muestra ni la más mínima señal de afecto por él, pues le recuerda demasiado al asesino de su amante; finalmente, fallece acusada de ingrata por todos, tras la feliz boda de don Garcerán con otra dama.

La mayor innovación de La ingratitud castigada respecto a los textos examinados se produce tras el regreso del protagonista a tierras valencianas. No obstante, ya en los primeros compases de la novela topamos con una diferencia sutil, que a la postre resultará decisiva: el galán por el que suspira la dama es el de peor categoría moral y recibe su merecido a manos del protagonista. Se trata de la semilla que hará germinar el final trágico de Gerarda, pues el rostro del homicida se le quedará tan grabado a fuego en la memoria que será incapaz de corresponder debidamente a las heroicidades de su futuro criado. Todo lo cual dota de sentido al título de la novela y supone la culminación de un proceso de reescritura en el que Castillo, como pedían los cánones de la imitatio, ha sabido adscribirse a una tradición sin dejar por ello de aportar

32 "La quinta de Laura [...] había sido publicada en Tiempo de regocijo y carnestolendas de Madrid, Madrid, Luis Sánchez, 1627, con el título de La quinta de Diana. Los libreros alteraron el nombre de la protagonista al coincidir con el de una de las piezas que también reeditaron de Lope de Vega, Las fortunas de Diana" (González Ramírez, Sobre la prínceps 72). 
su sello personal. Así, si por un lado no cabe duda del carácter bizantino de su narración (Grouzis Demory, La quinta 23), lo cierto es que dicha temática se supedita aquí al castigo ejemplar de Gerarda: la novela no trata así de las venturas y desventuras de una pareja de enamorados, sino de los infortunios de un joven y de la desdichada suerte de su amada por no apiadarse de él. De este modo, constituye el reverso del Bien hacer, así como una vuelta de tuerca al género bizantino en clave moralizante, gracias a un desenlace que rehúye la tópica unión amorosa, a la zaga de otras obras de signo similar escritas a partir sobre todo de los años veinte ${ }^{33}$.

En efecto, el largo aliento de la Viuda y su descendencia alcanza a la Ingratitud. Más que Guzmán el Bravo ${ }^{34}$, son sobre todo la comedia de Lope y la novela de Moreno las que mejor explican la hechura del relato que encabeza La quinta de Laura. Destaquemos por ejemplo la resistencia de Gerarda, que incluso solicita que la metan monja en un convento (así Clavela en La viuda), la exitosa fuga de don Garcerán (también su cofrade en la comedia escapa), la presencia de un segundo cautivo que toma parte activa en lides amorosas (Constanza en Castillo, Leonardo en Moreno), los cantos del cautivo en el jardín (como en La desdicha, pero asimismo en el Guzmán) o el final trágico de Gerarda (también la muerte espera a los amantes de Moreno, pero en su caso debido a su pertinaz constancia amorosa). En ninguno de estos trazos se observa un apego literal de Castillo hacia sus presumibles fuentes, sin que por ello resulten menos decisivas para la asunción del armazón argumental descrito.

Pese a dejarse empapar con regalo por sus lecturas, don Alonso no renunció a desandar sus propios pasos y volver los ojos al Bien hacer, aun sin perder nunca de vista la estela lopesca. Así, amén de las coincidencias argumentales entre ambas novelas, pueden rastrearse ciertos detalles narrativos y ecos verbales traspasados de una a otra. Dejando de lado por ahora la compartida laus urbis de Valencia y el común talante del rival amoroso, destaquemos las secuencias paralelas derivadas de la captura del galán: la descripción del

33 Para más detalles, puede verse Fernández Rodríguez (Entre corsarios 238-244 y 278-285).

34 Con todo, son varias las semejanzas compartidas por ambos relatos, sobre todo durante el cautiverio de Guzmán (si bien algunos rasgos se hallan también en estas otras fuentes, y en alguna más que indicaré), y sin duda Castillo conocía el relato de Lope, como bien señala Lepe García (El hibridismo 46). 
corsario $^{35}$, la venta de los cautivos ${ }^{36}$, la tristeza del protagonista durante la misma $^{37}$ y los rasgos del que será su comprador, descrito como uno de los moros más ricos de Argel, el cual "puso los ojos en él” (El bien hacer 209), expresión esta ("poniendo los ojos") que reaparece en la Ingratitud (94) en el mismo contexto ${ }^{38}$. El rol de la mora enamorada recae en un personaje del mismo nombre, Zelidora, hija del dueño en la Ingratitud y hermana de aquel en el Bien hacer. El cautivo, que ejerce de jardinero en ambas novelas, se esfuerza por trabajar con denuedo para granjearse el favor de sus amos ${ }^{39}$, $\mathrm{y}$ en efecto recibe mejor trato que sus compañeros. Entretanto, Zelidora se afana por lograr su amor y le insta a apostatar, tentándolo con las riquezas del dueño ${ }^{40}$, pero el cautivo se niega en redondo, ensalzando la religión cristiana y asumiendo los perjuicios físicos que le pueda ocasionar la arrojada defensa de su $\mathrm{fe}^{41}$. La reacción de la mora es muy similar en ambos textos:

35 “Gobernaba aquellas tres galeotas Alí Rustán, un corsario de los de más nombre en aquel tiempo" (La ingratitud 93); "Estaban en ella dos galeras de moros, que gobernaba Alí Morato, el mayor cosario de la morisma" (El bien hacer 208).

36 "Estos sacaron al siguiente día a vender en almoneda pública, y entre ellos al mariscal, al cual habían ya despojado del vestido con que fue cautivo" (La ingratitud 94); "Tomáronles las armas y despojándoles de todo lo bueno que tenían, fueron llevados a la ciudad, donde, en su gran plaza, se sacaron todos los cautivos a vender" (El bien hacer 208).

37 "[...] bien afligido de ver al término a que le había traído su adversa fortuna" ( $\mathrm{La}$ ingratitud 94); "Desconsolado estaba el pobre caballero, viendo la desgracia que le había sucedido" (El bien hacer 209).

38 Desde luego, es construcción habitual; en La libertad merecida (169), a la que atenderemos muy pronto, Castillo la emplea también respecto al futuro dueño del cautivo: "Puso el rey los ojos en don Vasco".

39 "Comenzó a cultivar los cuadros con cuidado, deseando agradar a sus dueños, para merecer su gracia" (La ingratitud 97); "Servía don Jerónimo en todo lo que le mandaban en casa con cuidado, sabiendo que esto era conveniente para negociar su buen tratamiento" ( $E l$ bien hacer 209).

$40 \quad$ "Tú me has parecido bien, y desearé que, dejando tu ley, admitas esta voluntad, recibiéndome por esposa tuya; que no me tiene mi padre tan poco amor que, viendo la elección acertada que hago en ti, no se tenga por dichoso en que seas quien herede su hacienda" ( $L a$ ingratitud 106); “.... que dejes tu ley y tomes la nuestra; que si lo haces te está mi hermano tan aficionado que te casará conmigo y dará la mayor parte de su hacienda para que aquí vivas estimado y querido de todos, como merece tu persona" (El bien hacer 210).

41 "[...] el haber de dejar mi ley, cosa que no haré aunque me ofrecieran cuantos tesoros hay en el mundo, porque la que profeso es la verdadera, y que ha de salvarnos a los cristianos. Esta es mi determinación, y lo será si mil siglos tuviese de vida, y esos los padeciese en más áspera prisión que la que tengo" (La ingratitud 107); “[ ...] por ser tan en daño de mi salvación, pues proponerme que siga una ley de tantos errores como la del Alcorán, naciendo 
"Estrañamente le pesó a Zelidora ver la resolución con que su esclavo la había hablado, mas supo disimular el pesar, pareciéndola que por primera vez se le podía sufrir aquel desprecio" (La ingratitud 107); "Mucho sintió Zelidora ver a su cautivo con tanta resolución, pero no desconfió por eso, considerando que [era] la primera vez de responder esto" (El bien hacer 210).

A partir de aquí, una y otra novela toman distintas veredas, pero aún pueden oírse algunos ecos, por ejemplo en la precaución del protagonista al llegar a Valencia: "El haber el mariscal ocultado su venida y pedido a cuantos con él venían que no la publicasen tuvo su fundamento, el cual fue querer ir primero a Valencia, y saber el estado de las cosas tocantes a la hermosa Gerarda" (La ingratitud 117); "No quiso don Jerónimo manifestarse a nadie en Valencia hasta saber en qué estado estaban las cosas de doña Laura" ( $E l$ bien hacer 215). Por lo demás, ambos galanes salvan a sus amadas de perecer en un incendio que se produce en una alquería a la que ellas habían acudido para solazarse. Castillo recupera uno de los primeros lances del Bien hacer, que en esta novela propiciaba el enamoramiento de los protagonistas, y lo transforma en una de las tres ocasiones en las que el mariscal, de nuevo en Valencia, acude en socorro de Gerarda ${ }^{42}$.

No era esta la primera vez que Castillo Solórzano revisitaba sus Noches de placer en busca de inspiración. Recordemos que Los encantos de Bretaña, comedia incluida en Fiestas del jardín (1634), es fruto de un proceso de reescritura de La cautela sin efecto, una de las novelas que integraba aquella colección (Sileri 220-47 y Fuentes Nieto, Fiestas 25-27). Que Castillo acudiera de nuevo a ella se antoja razonable: debió de ser obra bien recibida, según se infiere no porque las Noches se reeditaran como tales -el ritmo de publicación frenético con que Castillo saciaba a sus lectores impedía a menudo tal circunstancia (González Ramírez, Sobre la prínceps 69)-, sino porque en

yo entre católicos cristianos y sabiendo que la mía es la verdadera y las otras todo engaño, fuera, hacerlo, despeñarme a las eternas penas [...]. Yo os serviré el tiempo que fuere vuestro cautivo con el cuidado que veréis. Si por este fin he tenido diferente tratamiento que mis compañeros, con mi desengaño en este particular espero tener igualdad con ellos; y aunque sea más malo estoy dispuesto antes a padecerle que a desdecir de lo que debe quien por el agua del bautismo está en el gremio de los católicos" (El bien hacer 210).

42 En distintas circunstancias, también Feliciano salva tres veces la vida a Dorotea en la novela El socorro en el peligro, publicada en Tardes entretenidas en 1625 (Sileri 127 y Grouzis Demory, De las Tardes 175). En cuanto al incendio, cabe recordar también el que se provoca en No hay mal que no venga por bien (Jornadas alegres, 1626), entre otros. 
las Novelas amorosas de los mejores ingenios de España (1648), publicada apenas un año antes que La quinta de Laura, nada menos que tres de las cuatro novelas seleccionadas de Castillo pertenecían a este libro (las otras cuatro, ya lo sabemos, son las Novelas a Marcia Leonarda). Ignoramos las razones que empujaran a José Alfay y Martín Navarro -editores del volumena privilegiar esta colección, pero desde luego resulta muy significativa la confianza depositada en ella, más allá de que silenciaran no ya la procedencia de las cuatro novelas de Castillo, sino también el nombre del propio autor (a diferencia del de Lope, aireado en el prólogo, quizá porque bastaba para poner los dientes largos a los lectores), por entonces venido a menos literariamente y tal vez ya fallecido (González Ramírez, Lope de Vega).

Aclarada ya la deuda de la Ingratitud con el Bien hacer, conviene atajar un problema respecto al título de la primera. La crítica ha aducido que $L a$ quinta de Laura llegó a manos de su editor "casi con toda seguridad carente de algunos de los títulos de sus novelas" (González Ramírez, Sobre la prínceps 61). El asunto nos incumbe de primera mano, por cuanto tales sospechas han recaído sobre No hay mal que no venga por bien, idéntico título al de una novela muy distinta de Castillo perteneciente a Jornadas alegres (1626), y sobre La ingratitud castigada, cuyo nombre recuerda mucho al de La ingratitud y el castigo, estampada en Noches de placer (1631). Tanto Bourland (138) como González Ramírez (Sobre la prínceps 63) deducen que estas repeticiones no pueden deberse a Castillo. Hay razones para suponer lo contrario. La fantasma de Valencia, una de las comedias que el tordesillano compuso para Fiestas del jardín (1634), toma su título, idéntico, de una de sus novelas impresas nueve años antes en Tardes entretenidas (Monzó, Fiesta y teatro 68-69). Las circunstancias editoriales que envuelven al título global de la colección, $L a$ quinta de Laura, deben ponernos ciertamente sobre aviso; pero, en lo que atañe a estas novelas, las semejanzas onomásticas no minan la credibilidad de su autoría. Al fin y al cabo, tales remedos podían muy bien hacer las veces de reclamo para el público más fiel al vallisoletano ${ }^{43}$.

Como las dos Fantasmas, ambas Ingratitudes tan solo comparten la similitud onomástica, más allá del tema común que sus títulos permiten entrever.

43 Considérense unas palabras de Montero Reguera (167) respecto a las colecciones de novelas cortas, las cuales repiten "títulos parecidos o muy semejantes, que acaban convirtiéndose en una suerte de reclamo publicitario que los escritores y editores saben aprovechar muy bien". 
Ahora bien, resulta la mar de interesante que La ingratitud castigada, tejida a todas luces con la urdimbre de El bien hacer no se pierde, perteneciente a Noches de placer, evoque desde su título el nombre de otra novela incluida en esta misma colección. ¿Simples casualidades? No lo creo. Menos aún si advertimos que Noches de placer contiene una novela llamada La fuerza castigada (amén por cierto de otro ingrato: El ingrato Federico), conque el título elegido para La ingratitud castigada parece ser definitivamente fruto de este libro.

En cualquier caso, el sintagma que da nombre a la novela se desprende del propio texto sin mayor resistencia: en sus últimas páginas se insiste hasta en doce ocasiones en la ingratitud de la ingrata Gerarda. Por dos veces, de hecho, se relaciona su talante con el castigo de marras: "Yo he de ser quien la dé castigo que merece su mucha ingratitud"; "Conocida la suma ingratitud de Gerarda, se le había helado el amor que le tenía, cosa que dispuso el Cielo así para castigo, pena suya" (La ingratitud castigada 133). La mención del castigo no es tan recurrente como la de la ingratitud (solo se registran esas dos ocasiones), pues de hecho la condena no tiene lugar hasta el desenlace: Gerarda muere sola y vilipendiada por todos, mientras que su pretendiente y salvador se casa con otra dama. De este modo, el título escogido encaja a la perfección con el argumento, y tanto pudo deberse a la pericia del editor como, por qué no, a una decisión del propio Castillo, que por fuerza hubo de tener presentes las ingratitudes y la castigada de Noches de placer (y aun otras novelas suyas, como $\mathrm{El}$ soberbio castigado ${ }^{44}$, que confirma su querencia por tal sintagma), y a quien un título así le permitía hacer más hincapié aún en el juego intertextual, tan caro al autor. Sea como fuere, el título -no así el argumento- podría remitir asimismo a La ingratitud vengada: escrita a finales de los años ochenta y publicada en el seno de la Parte XIV en 1620, es nada menos que la única comedia de Lope citada en la primera parte del Quijote, circunstancia que, más allá de su discutida interpretación (Boadas), inmortalizaba el título para el devenir de nuestras letras. Pero no acaban aquí las tretas intertextuales de la novela. 


\section{LAS TESELAS QUE FALTABAN: LA LIBERTAD MERECIDA Y AMOR CON AMOR SE PAGA}

Tal y como advirtió Lepe García (El hibridismo 46), el episodio del cautiverio en La ingratitud castigada comparte varios motivos con La libertad merecida, cuarta novela de las Jornadas alegres (1626): el servicio a personajes de alto rango, el oficio de jardinero desempeñado por los cautivos, el amor que despiertan en las hijas de sus dueños y la presencia de triángulos amorosos. Ahora bien, un careo sistemático de ambos relatos permite observar que sus similitudes van más allá de estos lugares comunes del cautiverio literario. Ciertos detalles y calcos lingüísticos sugieren que Castillo volvió los ojos a $\mathrm{La}$ libertad merecida. Así, la tarea de jardinero se le encomienda al protagonista en términos muy similares: "trató de allí adelante de cultivar y componer los cuadros de aquel fresco y deleitoso sitio. [...] don Vasco fue señalado por el rey para servir de jardinero en compañía de otro cautivo, que era andaluz" (La libertad merecida 169-70); "Aquí, informado de otro cautivo andaluz que le dieron por compañero, comenzó a cultivar los cuadros" ( $\mathrm{La}$ ingratitud castigada 97). Más adelante topamos con un episodio trasplantado por Castillo de una novela a otra. Para aliviar sus penas, ambos protagonistas deciden cantar un soneto, pero, descuidados como están, ignoran que su ama los escucha: "Estaba un día el cautivo don Vasco igualando con unas tijeras una mesa de murta, que era adorno de un curioso cuadro del jardín; y por dar alivio a sus penas, quiso comunicarlas al aire, cantando en sonora voz" (La libertad merecida 171); "estaba igualando una mesa de murta con unas tijeras Guillermo [...]. Parose por oír lo que cantaba, y comenzaba este soneto, con dulce y sonora voz" (La ingratitud castigada 109) ${ }^{45}$. Como dos gotas de agua. La formulación de la secuencia es tan parecida ${ }^{46}$ que se antoja debida a una lectura muy fresca o a un recuerdo preciso de La libertad

$45 \quad$ En el Bien hacer (212) se menciona una ocupación similar (“Un día que estaba en el jardín este caballero componiendo una mesa de murta...”), pero ni la situación es análoga ni las huellas lingüísticas tan claras.

46 Según anotan Barella y Valvassori (171) en su edición de La libertad merecida, se trata de un "posible (y remoto) eco" de unos versos del romance "Ahora que estoy de espacio", de Góngora (151-55), que rezan así: "A todas quería bien, / con todas tenía ventura, / porque a todas igualaba / como tijeras de murtas". 
merecida, impresa en sus tempranas Jornadas alegres ${ }^{47}$. Castillo cerraba así el círculo volviendo a su primera novela sobre el cautiverio musulmán de carácter bizantino ${ }^{48}$. A esas alturas, el tordesillano sabía perfectamente a qué fuentes acudir para pertrecharse ante el lector con todas las de ganar. Ya no sorprende tanto que una de las novelas de La quinta de Laura, No hay mal que no venga por bien, lleve un título idéntico al de otra de Jornadas alegres.

¿Termina aquí el mosaico de reescrituras? No todavía. Resulta que el encomio de Valencia con el que da comienzo la Ingratitud presenta particulares similitudes con el que abre Amor con amor se paga (González Ramírez, Sobre la princeps 67), novela impresa en Los alivios de Casandra $(1640)^{49}$. Es cierto que tales descripciones se repiten una y otra vez en Castillo (Giorgi, Noches 202), sin ir más lejos en las primeras líneas del Bien hacer, aunque no con palabras tan parecidas. Ahora bien, hay razones para sospechar que Castillo debió de tener presente Amor con amor se paga a la hora de escribir la Ingratitud. La dama, llamada Gerarda en ambas novelas ${ }^{50}$, debe enfrentarse en uno y otro relato a su hermano, que quiere casarla con un galán al que ella desprecia, descrito como soberbio y presuntuoso, en términos por cierto parejos: "una presunción tan altiva que paró en soberbia y descortesía, con que no era muy bien querido en su patria" (La ingratitud castigada 78); "una

$47 \quad$ Entre otros detalles podrían citarse también los siguientes pasajes: "Partió Zulema con todo el despojo que ganó [...] y cautivos que vistió a su modo, salvo a don Vasco, que iba en el hábito mismo que le cautivó" (La libertad merecida 169); "[...] al mariscal, al cual habían ya despojado del vestido con que fue cautivo" (La ingratitud castigada 94).

48 Las novelitas de Castillo examinadas son las tres que Grouzis Demory (La quinta 24) clasifica como moriscas. A ellas Sileri añade con acierto El inobediente (también de Noches de placer), puesto que recrea asimismo un episodio de cautiverio a la bizantina. Esta novela carece de mayor interés aquí: presenta algunos lances tan parecidos a los nuestros como tópicos por aquel entonces.

$49 \quad$ "Valencia, ilustre ciudad de España, celebrada por su nobleza, por sus lucidos ingenios, por sus hermosas damas y, sobre todo, por ser erario de gloriosos cuerpos de santos, hijos suyos, que con su vida y milagros favorecieron a su patria" (La ingratitud castigada 78); "Valencia, insigne y antigua ciudad de España, ilustre por su nobleza, rica por sus tratos, célebre por sus ingenios, santa por ser divino sagrario de cuerpos santos hijos suyos y famosa por sus hermosas damas, fue patria de la singular hermosura de Gerarda, bizarra dama entre las que honran el sagrado Turia" (Amor con amor se paga 86v).

50 En Amor con amor se paga, el nombre de Garcerán le corresponde no a su pretendiente, sino al escudero. Huelga decir que, naturalmente, ambos nombres aparecen en otros textos de Castillo (el de Gerarda, que ya ha asomado en el Lisardo, es también el de una de las damas del marco narrativo de Los alivios). 
presunción soberbia que tenía, [...] con que no era muy bien quisto en la ciudad" (Amor con amor se paga $87 \mathrm{r})^{51}$. En las dos novelas (lo mismo que en el Bien hacer), el portador de tales cualidades negativas es quien termina por malograrse; de hecho, la caída moral de la Gerarda de la Ingratitud se fragua al favorecer al galán equivocado, y se remata al no corresponder al de mejores partes. $\mathrm{O}$ lo que es lo mismo, al contravenir la máxima expresada justamente en Amor con amor se paga.

Poco sorprende que Castillo retomara también de esta novela ciertos detalles para modelar La ingratitud castigada. Al fin y al cabo, ambas colecciones, Los alivios de Casandra y La quinta de Laura, presentan no pocos rasgos en común y aun ecos literales (Bresadola y Gallo 83-84), así como una serie de innovaciones que permiten "conjeturar que ambas responden a un proyecto creativo común” (Lepe García, El último 350). El caso aquí revelado diría que confirma las conclusiones de la crítica acerca de estas dos colecciones (las últimas de Castillo, pues la aprobación de Sala de recreación data de 1639). "Obras de un apasionado devorador de libros, las historias solorzanianas se antojan como un crisol de sugestiones y reescrituras propias y ajenas" (Mulas).

\section{LA HERENCIA DE LA VIUDA}

Agua pasada mueve molino. Que se lo pregunten si no a Castillo Solórzano, experto consumado en el ardid de la reescritura y dotado de una irremediable "propensione all'autocitazione" (Gallo 93), mañas estas -se las sabía todas el tordesillano-que le permitieron visitar los tórculos con inusitada frecuencia. En El bien hacer no se pierde y La ingratitud castigada decidió hilvanar el hilo argumental de La viuda, casada y doncella y Guzmán el Bravo, no sin renunciar, en el segundo de los casos, a su rica y acostumbrada auto-reescritura. Renovaba así la fórmula bizantina que Lope, en la Viuda y en otras comedias, tanto había contribuido a popularizar entre el gran público desde su juventud. Llevaba razón Sileri (205): en las novelitas cortas bizantinas de moros y cautivos firmadas por Castillo, "il termine di paragone più immediato non è il romanzo bizantino bensì la commedia".

51 El carácter de ambos caballeros coincide asimismo con el de don Cotaldo Corella, el rival amoroso en el Bien hacer, pero solo en parte y no tan al pie de la letra. 
Cuando mediaba el Seiscientos, la amenaza de los corsarios, las tentaciones del cautiverio y las idas y venidas de corte bizantino no estaban ya tan en boga. Sin embargo, en el terreno de la novela corta, género editorial en cierto declive, tales argumentos conservaban aún su modesta parcela. Poco antes que Castillo, María de Zayas acababa de sembrarla en 1647 mediante La esclava de su amante, novela también de raigambre lopesca incluida en la Parte segunda del sarao y entretenimiento honesto ${ }^{52}$. Aunque sea arriesgado inferir una relación entre uno y otro proceder, ciertamente muy cercanos en el tiempo, ambos casos ilustran la honda huella del teatro de Lope, en particular de sus comedias bizantinas, entre los más reputados cultivadores de la novela corta al arrimo del ecuador del siglo XVII.

\section{BIBLIOGRAFÍA}

Barella, Julia y Mita Valvassori, eds. "La libertad merecida". Jornadas alegres, de Alonso de Castillo Solórzano. Madrid: SIAL, 2019. 164-90.

Boadas, Sònia, ed. La ingratitud vengada. Comedias de Lope de Vega. Parte XIV. Coord. José Enrique López Martínez. Madrid: Gredos, 2015. Tomo 2. 911-1047.

Bonilla Cerezo, Rafael. "Alonso de Castillo Solórzano: bio-bibliografía completa". Tintas. Quaderni di letterature iberiche e iberoamericane 2 (2012): 243-82.

Bourland, Caroline B. The short story in Spain in the seventeenth century. Northampton: Smith College, 1927.

Bresadola, Andrea. "El modelo italiano y su superación en Los alivios de Casandra de Castillo Solórzano”. Criticón 135 (2019): 143-60.

Camamis, George. Estudios sobre el cautiverio en el Siglo de Oro. Madrid: Gredos, 1977.

Campana, Patrizia, ed. Tardes entretenidas, de Alonso de Castillo Solórzano. Barcelona: Montesinos, 1992.

Castillo Martínez, Cristina. "Falsificaciones literarias y editoriales en la novela corta del siglo XVII”. Imposturas literarias españolas. Ed. Joaquín Álvarez Barrientos. Salamanca: Universidad de Salamanca, 2011. 33-55.

"La escritura hagiográfica de Castillo Solórzano: el Sagrario de Valencia (1635)". Edad de Oro 36 (2017): 59-73.

"La Arcadia en el Lisardo enamorado: Castillo Solórzano, lector de Lope". Criticón 135 (2019): 97-111.

$52 \quad$ Se ha identificado su fuente en la comedia de Lope titulada Virtud, pobreza y mujer (Fernández Rodríguez, Las cosicosas). 
Castillo Solórzano, Alonso de. "Amor con amor se paga". Los alivios de Casandra. Barcelona: Jaime Romeu, 1640. 86v-120r.

"El bien hacer no se pierde". Noches de placer. Ed. Giulia Giorgi. Madrid: SIAL, 2013. 201-20.

Escarmientos de amor moralizados. Sevilla: Manuel Sande, 1628.

"La ingratitud castigada". La quinta de Laura. Ed. Christelle Grouzis Demory. Madrid: Verbum, 2014.

"La libertad merecida". Jornadas alegres. Eds. Julia Barella y Mita Valvassori.

Madrid: SIAL, 2019. 164-90.

Lisardo enamorado. Ed. Eduardo Juliá y Martínez. Madrid: Gráficas Ultra, 1947. Noches de placer. Ed. Giulia Giorgi. Madrid: SIAL, 2013.

Cayuela, Anne y Pascal Gandoulphe. "Littérature et pouvoir : dédicaces et dédicataires dans Noches de placer, d'Alonso Castillo Solórzano (1631)”. Bulletin Hispanique 101.1 (1999): 91-110.

Collantes Sánchez, Carlos M., Emre Özmen y Pedro Ruiz Pérez. "La figuración autorial de Castillo Solórzano". Criticón 135 (2019): 5-27.

Copello, Fernando. "Cuestiones de gusto, mercado y costos: la transformación de La desdicha por la honra de Lope en Los amantes sin fortuna (Madrid, 1666)". Edición y literatura en España (siglos XVI y XVII). Ed. Anne Cayuela. Zaragoza: Prensas Universitarias de Zaragoza, 2012. 269-87.

Di Pastena, Enrico. "La Séptima parte: historia editorial". Comedias de Lope de Vega. Parte VII. Coord. Enrico Di Pastena. Lérida: Milenio/Universitat Autònoma de Barcelona, 2008. Vol. 1, 9-65.

Escudero Baztán, Juan Manuel. "Reescrituras dramáticas áureas de La fuerza de la sangre de Cervantes". Anales cervantinos 45 (2013): 155-74.

Feit, Ronna S. “An Episode in Vicente Espinel's Marcos de Obregón taken from Lope de Vega". Bulletin of the Comediantes 50.2 (1998): 365-70.

Feit, Ronna S. y Donald McGrady, ed. Viuda, casada y doncella, de Lope de Vega. Newark: Juan de la Cuesta, 2006.

Fernández Rodríguez, Daniel. "Lope de Vega se reescribe: de la comedia bizantina a la novela corta (La viuda, casada y doncella, Guzmán el Bravo y La prudente venganza)". Bulletin of the Comediantes 70.2 (2018): 33-48.

"Las cosicosas de doña María: ecos de Virtud, pobreza y mujer, Lope y otros ingenios en La esclava de su amante de Zayas (y unos apuntes sobre la Parte veintecinco perfeta y verdadera)". eHumanista 38 (2018): 627-40.

"La viuda, casada y doncella, de Lope, fuente de La desdicha en la constancia, novela corta bizantina de Miguel Moreno (con unas notas sobre La Circe)". Rilce 35.3 (2019): 875-95.

Entre corsarios y cautivos: las comedias bizantinas de Lope de Vega, su tradición y su legado. Madrid/Frankfurt am Main: Iberoamericana/Vervuert, 2019.

Ferrer Valls, Teresa, dir. Diccionario biográfico de actores del teatro clásico español (DICAT). Kassel: Reichenberger, 2008. 
Festini, Patricia. "Fiestas del jardín de Castillo Solórzano: el teatro como centro de la celebración”. Texturas 11 (2011): 211-23.

Fuentes Nieto, Juan Luis. "Alonso de Castillo Solórzano. Evolución literaria y compromiso teatral en las Fiestas del jardín". "Sapere aude". Actas del III Congreso Internacional Jóvenes Investigadores Siglo de Oro (JISO 2013). Eds. Carlos Mata Induráin, Adrián J. Sáez y Ana Zúñiga Lacruz. Pamplona: Universidad de Navarra, 2014. 111-21. ed. Fiestas del jardín, de Alonso de Castillo Solórzano. Madrid: SIAL, 2019.

Gallo, Antonella. Virtuosismi retorici barocchi: novelle con lipogramma. Florencia: Alinea, 2003. Giorgi, Giulia. ed. Noches de placer, de Alonso de Castillo Solórzano. Madrid: SIAL, 2013. "Alonso de Castillo Solórzano reescritor de sí mismo: algunas notas sobre los Escarmientos de amor moralizados y el Lisardo enamorado". Edad de Oro 33 (2014): 257-66.

"El Lisardo enamorado de Alonso de Castillo Solórzano: una novela, múltiples géneros". Nuevos enfoques sobre la novela corta barroca. Eds. Mechthild Albert, Ulrike Becker, Rafael Bonilla Cerezo y Angela Fabris. Frankfurt am Main: Peter Lang, 2016. 247-60.

Góngora, Luis de. Antología poética. Ed. Antonio Carreira. Barcelona: Crítica, 2009.

González Ramírez, David. "Lope de Vega y Castillo Solórzano: "Los mejores ingenios de España". Consideraciones críticas sobre la transmisión, la compilación y la repercusión de las Novelas amorosas (Zaragoza, 1648)". Alazet 19 (2007): 27-54.

"Una novela corta del Siglo de Oro rescatada: La desdicha en la constancia (Madrid, 1624) de Miguel Moreno". Voz y letra: revista de literatura 23.1 (2012): 25-66.

González Ramírez, David. "Sobre la prínceps de dos textos póstumos de Castillo Solórzano: Sala de recreación y La quinta de Laura". Novela corta y teatro en el Barroco español (1613-1685). Studia in honorem prof. Anthony Close. Eds. Rafael Bonilla Cerezo, José Ramón Trujillo y Begoña Rodríguez. Madrid: SIAL, 2012, 55-76.

"Madrid, 1620. De la carrera editorial al nacimiento de un nuevo escritor: Alonso Castillo Solórzano y la narrativa de su tiempo". Criticón 135 (2019): 29-48.

González Rovira, Javier. “La novela bizantina española. Características y desarrollo”. Tesis doctoral. Universitat de Barcelona, 1995.

La novela bizantina de la Edad de Oro. Madrid: Gredos, 1996.

Grouzis Demory, Christelle, ed. La quinta de Laura, de Alonso de Castillo Solórzano. Madrid: Verbum, 2014.

"De las Tardes entretenidas (1625) a La quinta de Laura (1649): apuntes sobre la evolución narrativa de Castillo Solórzano”. Creneida 7 (2019): 168-87.

Iriso Ariz, Silvia. "Estudio de la colección Gálvez: fiabilidad y sentido de los apógrafos de Lope de Vega". Anuario Lope de Vega 3 (1997): 99-143.

LaGrone, Gregory G. "Castillo Solórzano's Escarmientos de amor moralizados". Hispania, 22.1 (1939): 61-67.

Lepe García, Ma Rocío. "El hibridismo genérico en La Quinta de Laura de Castillo Solórzano, I. La impronta bizantina”. Etiópicas 4 (2008): 21-76. 
"El último Castillo Solórzano: hacia un modelo innovador del marco narrativo". Compostella aurea. Coords. Antonio Azaustre Galiana y Santiago Fernández Mosquera. Santiago de Compostela: Universidade de Santiago de Compostela, 2011. Tomo 2. 347-54.

López Gutiérrez, Luciano. “Donaires del Parnaso de Alonso de Castillo Solórzano: Edición, estudio y notas”. Tesis doctoral. Universidad Complutense de Madrid, 2003.

Montero Reguera, José. "El nacimiento de la novela corta en España (la perspectiva de los editores)". Lectura y signo: Revista de literatura 1 (2006): 165-75.

Monzó, Clara. "Fiesta y teatro en el seiscientos valenciano: La fantasma de Valencia de Alonso de Castillo Solorzano”. Universitat de València, 2014.

"Un dramaturgo en busca de mecenas: escritura y patrocinio en La fantasma de Valencia (1634) de Alonso de Castillo Solórzano". El legado hispánico. Manifestaciones culturales y sus protagonistas. Eds. Abel Lobato Fernández, Esperanza de los Reyes Aguilar, Irene Pereira García y Cristina García González. León: Universidad de León, 2017. Vol. 2. 51-68.

"Un mapa estilizado de la ciudad áurea: el caso de La fantasma de Valencia (1634) de Alonso de Castillo Solórzano". Topografias literarias: el espacio en la literatura hispánica de la Edad Media al siglo XXI. Eds. Alba Agraz Ortiz y Sara Sánchez-Hernández. Madrid: Biblioteca Nueva, 2017. 141-47.

Morley, S. Griswold y Courtney Bruerton. Cronología de las comedias de Lope de Vega. Madrid: Gredos, 1968.

Mulas, Margherita. "Huellas italianas en Los amantes andaluces de Alonso de Castillo Solórzano". Criticón 136 (2019): 23-41.

Presotto, Marco, ed. Novelas a Marcia Leonarda, de Lope de Vega. Madrid: Castalia, 2007.

Rubio Árquez, Marcial. "Huerta de Valencia: entre la colección de novelas y el cancionero de academia”. Edad de Oro 36 (2017): 45-58.

Sileri, Manuela. "Le novelas cortas di Alonso de Castillo Solórzano tra narrativa e teatro". Tesis doctoral. Università degli Studi di Pisa, 2008.

Teijeiro Fuentes, Miguel Ángel. Moros y turcos en la narrativa áurea (el tema del cautiverio). Cáceres: Universidad de Extremadura, 1987.

Vaccari, Debora. "Lope de Vega y la reescritura de la novela corta: el caso de Amar sin saber a quién". Novela corta y teatro en el Barroco español (1613-1685): Studia in honorem Prof. Anthony Close. Eds. Rafael Bonilla Cerezo, José Ramón Trujillo y Begoña Rodríguez. Madrid: Sial, 2012. 87-105.

Vega, Lope de. "Guzmán el Bravo". Novelas a Marcia Leonarda. Ed. Marco Presotto. Madrid: Castalia, 2007. 197-245.

Laurel de Apolo. Ed. Antonio Carreño. Madrid: Cátedra, 2007.

Relación de las fiestas que la insigne villa de Madrid hizo en la canonización de su bienaventurado hijo y patrón san Isidro [...]. Madrid: Viuda de Alonso Martín, 1622.

Viuda, casada y doncella. Eds. Ronna S. Feit y Donald McGrady. Newark: Juan de la Cuesta, 2006. 